\title{
Gastric accommodation in non-ulcer dyspepsia and the roles of Helicobacter pylori infection and vagal function
}

\author{
M Thumshirn, M Camilleri, S B Saslow, D E Williams, D D Burton, R B Hanson
}

\begin{abstract}
Background-The pathophysiological mechanisms in non-ulcer dyspepsia are incompletely understood.

Aims-To compare gastric motor and sensory functions in Helicobacter pylori positive or negative patients with nonulcer dyspepsia.

Patients-Seventeen patients with nonulcer dyspepsia and 16 asymptomatic controls.

Methods-The following were evaluated: gastrointestinal symptoms; gastric emptying and orocaecal transit of solids; abdominal vagal function; gastric compliance; fasting and postprandial gastric tone and phasic contractions; symptoms during ingestion of cold water and during the distension of an intragastric bag; and somatic sensitivity and personality profile (Minnesota Multiphasic Personality Inventory, MMPI).

Results-Gastric accommodation was reduced in $H$ pylori negative dyspeptics relative to controls; the degree of accommodation was unrelated to $H$ pylori status in dyspeptics. Increased postprandial gastric sensation was more frequent among $H$ pylori positive patients (4/5 H pylori positive versus $4 / 12 H$ pylori negative patients). Intragastric meal distribution and orocaecal transit were normal; gastric emptying at four hours was abnormal in 4/17 patients. Vagal dysfunction was rare. Eight of 17 patients had somatisation or depression on MMPI.

Conclusion-Impaired gastric accommodation is frequent in non-ulcer dyspepsia and seems to be unrelated to vagal efferent dysfunction. H pylori infection does not seem to influence gastric accommodation, but is associated with heightened sensitivity in dyspeptics. Therapeutic approaches that restore normal postprandial accommodation and gastric sensitivity should be tested in non-ulcer dyspepsia.

(Gut 1999;44:55-64)
\end{abstract}

Keywords: non-ulcer dyspepsia; Helicobacter pylori; vagal function

Non-ulcer dyspepsia is a symptom complex characterised by postprandial upper abdominal discomfort or pain, early satiety, nausea, vomiting, abdominal distension, bloating, and anorexia in the absence of organic disease. ${ }^{1}$ It is a common clinical problem encountered by primary internists and gastroenterologists. ${ }^{2}$ Gastric motor abnormalities, altered symptom threshold, psychosocial factors, and Helicobacter pylori infection are considered important aetiological mechanisms. ${ }^{3}$

Gastric motor abnormalities such as delayed emptying, ${ }^{45}$ impaired initial distribution of a meal within the stomach, ${ }^{6}$ antral hypomotility, ${ }^{7}$ reduced compliance, ${ }^{8}$ and altered myoelectric activity, ${ }^{9}{ }^{10}$ have been identified in subgroups of patients with non-ulcer dyspepsia. These abnormalities do not always correlate temporally with symptoms. Impaired accommodation, a disturbance of "diastolic" function of the stomach, has been suggested in one published study in which the average intragastric pressure during distension after a meal was assessed. ${ }^{11}$ However, the accommodation response or volume change of the stomach after meal ingestion was not evaluated in that study. The similarity of the effects on gastric motor function observed after surgical vagotomy ${ }^{11}$ led the authors to suggest that vagal dysfunction was responsible for the observed dysfunction in non-ulcer dyspepsia.

Other studies have evaluated sensory function in dyspeptic patients ${ }^{12-14}$ in the fasting state. In view of the normal gastric compliance, increased sensation during gastric distension suggested abnormal afferent function or the irritable stomach syndrome. ${ }^{13}$ Compliance reflects elastic and tonic properties of the stomach; however, it may not accurately predict the postprandial state of the stomach. Hence the influence of gastric tone on sensitivity of the stomach has not been fully elucidated.

Psychological disturbances are frequent in patients at the time of presentation with functional gastrointestinal disorders. ${ }^{15} 16$ The influence of these disorders on physiological functions in patients with non-ulcer dyspepsia is unclear.

The association of $H$ pylori infection and gastritis is well established. ${ }^{17} \mathrm{H}$ pylori infection seems to be unassociated with impaired gastric emptying ${ }^{6}{ }^{18} ;$ H pylori infection is not associated with gastric hypersensitivity, ${ }^{19}$ but its effect on gastric accommodation is unclear. Thus, two aspects of the pathophysiology and mechanism of non-ulcer dyspepsia remain unclear: (1) the accommodation and phasic contractile response of the proximal stomach to meal ingestion; and (2) the associations of $H$ pylori

Abbreviations used in this paper: MMPI, Minnesota Multiphasic Personality Inventory; NUD, non-ulcer dyspepsia; IBS, irritable bowel syndrome; BMI, body mass index; $I Q R$, interquartile range. 
infection and vagal dysfunction on proximal gastric motor functions.

Our hypotheses were that $H$ pylori infection reduces gastric accommodation but does not alter gastric emptying sensitivity, whereas $H$ pylori negative dyspepsia is due exclusively to impaired gastric emptying. Our aim was to study the sensorimotor functions of the stomach in asymptomatic controls and in patients with non-ulcer dyspepsia with or without evidence of current $H$ pylori infection. The motor functions evaluated included: gastric emptying of solids, initial distribution of the meal within the stomach, orocaecal transit, abdominal vagal function, and proximal gastric accommodation to meal ingestion. To assess gastric sensory function we measured perception of gastric distension and the volume of cold water that induced abdominal fullness.

\section{Materials and methods}

PATIENTS AND ASYMPTOMATIC CONTROLS

Seventeen patients with non-ulcer dyspepsia (12 $H$ pylori negative, five $H$ pylori positive) and 16 asymptomatic individuals (eight $H$ pylori negative, eight $H$ pylori positive) participated in the study after signing informed consent. The protocol for the study had been approved by the Institutional Review Board of the Mayo Clinic. Females of childbearing potential were required to have a negative plasma beta human chorionic gonadotrophin pregnancy test within 48 hours of study.

Patients with non-ulcer dyspepsia were recruited from the outpatient Gastroenterology Clinic of the Mayo Medical Center, Rochester, Minnesota. Inclusion criteria for patients with non-ulcer dyspepsia were: (a) at least two of the following symptoms related to meal ingestion: upper abdominal pain or discomfort, bloating, nausea, vomiting, and early satiety; (b) symptom duration of more than six months, occurring at least three times per week; (c) no evidence of ulceration (break in epithelial lining more than $5 \mathrm{~mm}$ diameter) or more than two erosions (each not more than 4 $\mathrm{mm}$ diameter) on upper gastrointestinal endoscopy; (d) normal abdominal ultrasonography; (e) no evidence of organic or systemic disease known to affect gastrointestinal motility or major psychiatric disturbances; $(f)$ absence of nocturnal gastro-oesophageal reflux symptoms or reflux symptoms postprandially; $(g)$ absence of previous abdominal surgery except for uncomplicated appendectomy, cholecystectomy, or hernia repair; (h) no intake of antibiotics, bismuth salts, steroids, or non-steroidal anti-inflammatory drugs in the preceding four weeks; (i) cessation of all medications that might influence gastrointestinal sensorimotor function at least 48 hours prior to the study.

The asymptomatic controls were recruited from the local community by public advertisement. Screening for $H$ pylori infection was performed using a serological test for $H$ pylori. Following further confirmation of $H$ pylori status as described below, the first eight consecutive $H$ pylori negative subjects (four women, four men; age range 19-58 years) and the first eight $H$ pylori positive subjects (five women, three men; age range 27-45 years) were enrolled for further study. None had undergone previous abdominal surgery except for uncomplicated appendectomy. None was taking medications with the exception of oral contraceptives. Clinical interview and a validated screening questionnaire (the Bowel Disease Questionnaire ${ }^{20}$ ) were used to exclude subjects with significant gastrointestinal symptoms. The physiological observations on asymptomatic volunteers have been published elsewhere ${ }^{33}$ and are included here only where comparisons are made with the results in patients with functional dyspepsia. The observations in asymptomatic controls are not discussed in this paper.

ASSESSMENT OF H PYLORI STATUS

All patients and healthy volunteers underwent serological testing (PYLORI ELISA II, BioWhittaker, Walkersville, Maryland, USA) and upper gastrointestinal endoscopy to obtain eight antral biopsy specimens for assessing $H$ pylori status. $H$ pylori infection was diagnosed if two of the following three tests were positive: (1) H pylori IgG antibodies in serum as determined by ELISA; (2) histology using Giemsa stain and haematoxylin and eosin from four antral biopsy specimens; and (3) bacteriological culture of four antral biopsy specimens performed on Brucella based media (containing haem, vancomycin, trimethoprim, polymyxin $\mathrm{B}$, defibrinated sheep blood, vitamin $\mathrm{K}$, and actidione). Patients and asymptomatic controls were considered negative for $H$ pylori if all three tests were negative. After the study, patients and controls were offered treatment for eradication of $H$ pylori infection with explanation that it was unclear whether this was clinically indicated from the currently published guidelines and literature.

ASSESSMENT OF GASTROINTESTINAL AND

PSYCHOLOGICAL SYMPTOM PROFILES

A comprehensive, modified bowel disease questionnaire assembled from previously validated instruments (the Bowel Disease Questionnaire ${ }^{20}$ ) was used to assess symptomatology in all participants (patients and asymptomatic controls). The Minnesota Multiphasic Personality Inventory (MMPI) ${ }^{21}$ was used to screen for psychological disorders in all participants. The data obtained from the MMPI were analysed using a validated computer program ${ }^{22}$ and assessed by a staff psychologist coinvestigator (DEW).

MEASUREMENT OF GASTRIC AND OROCAECAL TRANSIT

The transit studies were performed after an overnight fast on a day separate from all other studies. We quantitated gastric and small bowel transit by means of a validated scintigraphic method that utilises technetium-99m radiolabelled pellets (Amberlite 410, Sigma Chemical Co., St Louis, Missouri, USA) in an egg meal (0.92 MJ). The preparation, conduct, and analysis of transit studies have been previously published. ${ }^{23}$ Briefly, patients ingested the egg meal after an overnight fast; scans of the 
abdomen were obtained with the patient standing using an anterior and posterior large field of view gamma camera (GE Starcam, Milwaukee, Wisconsin, USA). Images were obtained immediately after the meal, and two, four, and six hours later. ${ }^{24} \mathrm{~A}$ second nonradiolabelled, standardised solid-liquid meal (2.24 MJ) was ingested after the four hour scan. A region of interest program was used to quantitate radioactivity within the stomach and colon. Corrections were made for isotope decay and for tissue attenuation by calculation of the geometric mean of counts obtained using anterior and posterior images. Gastric emptying was expressed as the percentage isotope remaining in the stomach at two and four hours. ${ }^{24}$ The more sensitive index for gastric emptying delay is the percentage emptied at four hours. ${ }^{24}$ Orocaecal transit was estimated by the percentage colonic filling at six hours. ${ }^{24}$

ASSESSMENT OF VAGAL FUNCTION

Efferent vagal function ${ }^{25} 26$ was tested by the plasma pancreatic polypeptide ${ }^{27}$ response during 30 minutes of modified sham feeding - that is, chewing and spitting a bacon and cheese toasted sandwich. The sham feeding test is less sensitive but more specific for vagal dysfunction than the alternative insulin hypoglycaemia test. ${ }^{28}$ The sandwich was cooked on a hotplate with the patient or asymptomatic control present. Subjects were instructed to extend the neck slightly to avoid swallowing any food during modified sham feeding. Five $\mathrm{ml}$ blood samples for pancreatic polypeptide were collected into chilled EDTA vacutainers, once at baseline before sham feeding, and then at minutes $0,5,10,15,20,25$, and 30 during the sham feeding. Plasma concentrations of pancreatic polypeptide were determined by a validated and specific radioimmunoassay. ${ }^{27} \mathrm{~A}$ change from baseline of greater than $25 \mathrm{pg} / \mathrm{ml}$ is considered normal ${ }^{26}$; failure of plasma pancreatic polypeptide levels to increase by more than $25 \mathrm{pg} / \mathrm{ml}$ after modified sham feeding suggests abdominal vagal dysfunction. ${ }^{4}{ }^{29}$

MEASUREMENT OF PROXIMAL GASTRIC TONE The tone of the proximal stomach ${ }^{30}$ was assessed by a barostatic device (Distender Series II, G\&J Electronics Inc., Willowdale, Ontario, Canada). A double lumen assembly was inserted through the mouth such that a finely folded one litre capacity spherical polyethylene bag (Hefty Baggies, Mobil Chemical Company, Pittsford, New York, USA) at the end of the polyvinyl tube was positioned within the proximal stomach under fluoroscopic control. The baseline operating pressure within the polyethylene bag for each individual was set $1 \mathrm{~mm} \mathrm{Hg}$ above the pressure at which the bag volume was greater than 30 $\mathrm{ml}$, as in other papers in the literature. ${ }^{31-33}$ Velocity of air inflation was $25 \mathrm{ml} / \mathrm{sec}$. The method of measuring proximal gastric motility was similar to that successfully used in previous studies in our laboratory. ${ }^{32-34}$ The range of baseline operating pressure was $5-11 \mathrm{~mm} \mathrm{Hg}$.

Briefly, the polyethylene bag which is infinitely compliant at the inflation volumes observed in this study, is kept under constant pressure within the proximal stomach by means of the electronic barostat. Changes in volume within the bag reflect changes in gastric contractility. Two types of contractile responses can be detected: firstly, slow baseline volume variation that reflects relaxation (increased baseline volume) or increased contraction (decreased baseline volume); and secondly, phasic volume fluctuations (more than $5 \mathrm{ml}$ over baseline; 5-40 seconds duration) from the baseline volume which reflect contractions superimposed on the background state of contractility. This background contractility is summarised as "tone" to reflect terminology used in the published literature..$^{30-32}$

\section{MEASUREMENT OF PROXIMAL GASTRIC}

\section{COMPLIANCE}

Gastric compliance was assessed as the volume response to $2 \mathrm{~mm} \mathrm{Hg}$ stepwise increments of intrabag pressure at 30 second intervals up to $12 \mathrm{~mm} \mathrm{Hg}$ above the baseline operating pressure, or until the subject perceived abdominal pain. The bag was then deflated $(2 \mathrm{~mm} \mathrm{Hg}$ steps at 30 second intervals) until the intrabag pressure returned to the previous baseline operating pressure.

ASSESSMENT OF PERCEPTION DURING GASTRIC MECHANICAL DISTENSIONS

Gastric sensory function was assessed in the fasting state and twice postprandially by three intermittent increases in intrabag pressure of 4 , 8, and $12 \mathrm{~mm} \mathrm{Hg}$ above baseline operating pressure. The order of pressure distensions was randomised; each phasic pressure increment was maintained for one minute with a two minute interval when the intrabag pressure was deflated to the baseline operating pressure. Subjects received a standardised information sheet prior to sensory testing and a seven point adjectival perception scale was reviewed with them. Thereafter, there was minimal interaction between the subjects and investigators to avoid introducing any bias. The perceptions of three symptoms were recorded: nausea, fullness, and abdominal discomfort (or pain for grades 5 and 6 of discomfort). Symptoms were graded as follows: $0=$ none; $1=$ vague; $2=$ mild; 3 = moderate; $4=$ severe $5=$ very severe; $6=$ worst ever. The subjects were asked to record their perceptions 30 seconds after the onset of each one minute distension. This method of sensory assessment has been used extensively in this laboratory and has been shown to be responsive to physiological or pharmacological perturbations, and to be reproducible in previous studies in the human stomach $^{34}$ and colon. ${ }^{35} 36$

The same randomised sequence of phasic distensions was repeated twice postprandially: firstly, in the early postprandial period when the bag volume had returned to 2.5 times the average fasting volume measured on line or at 20 minutes after the standardised meal, whichever occurred first. Distensions were not performed earlier after the meal in order to allow for adequate assessment of the accommodation response to the meal. A second assessment of 

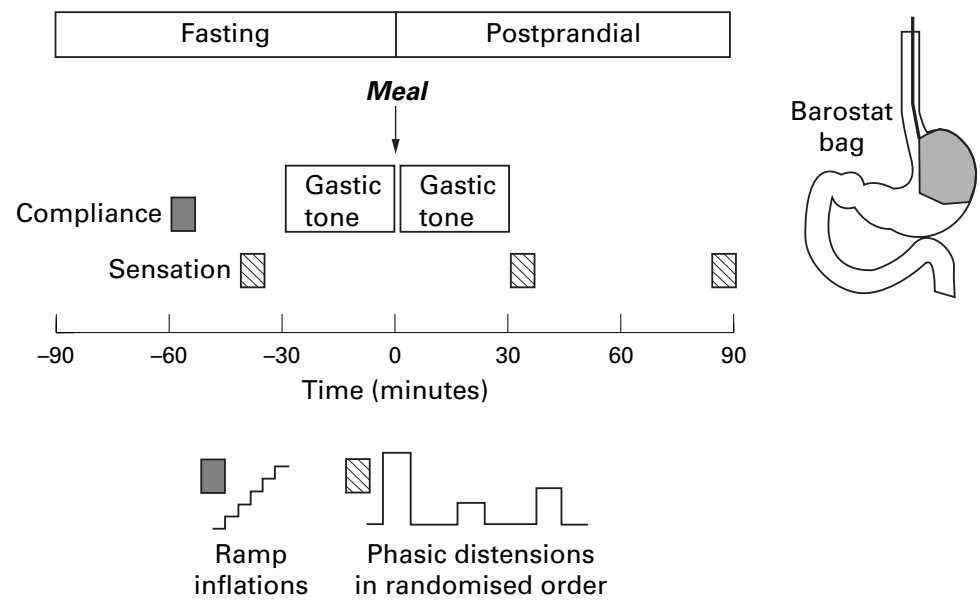

Figure 1 Experimental design for measurement of gastric compliance, tone, and sensation using a barostatically controlled polyethylene bag in the proximal stomach.

sensory function in the late postprandial period was performed when the bag volume had returned to fasting levels, or at least 90 minutes after the meal, whichever occurred first.

WATER BOLUS TEST

We measured the volume of cold tap water that could be ingested over a five minute period before the perception of abdominal fullness. This approach was described in a recent preliminary report as a simple non-invasive test of gastric sensitivity. ${ }^{37}$ Subjects were fasting for at least three hours prior to this test.

MEASUREMENT OF SOMATIC SENSITIVITY BY THE COLD STRESS TEST

Subjects were asked to immerse the nondominant hand up to the wrist in ice cold water $\left(0^{\circ} \mathrm{C}\right)$ for a maximum of five minutes or as long as they could tolerate the cold pain. The responses assessed were the maximum duration of pain tolerance in seconds and the pain intensity using a $100 \mathrm{~mm}$ visual analogue scale. ${ }^{38}$

EXPERIMENTAL PROTOCOL

All subjects were admitted to the General Clinical Research Center at St Mary's Hospital for tests that were performed over a period of three days. The intubated studies (gastric tone, gastric compliance, gastric sensation; see fig 1) were performed following an overnight fast. The double lumen tube assembly with the bag folded was introduced perorally and positioned in the proximal stomach under fluoroscopic control. The polyethylene bag was then slowly inflated with $500 \mathrm{ml}$ of air via a syringe to unfold it and immediately deflated. The subjects were seated upright in an armchair and the double lumen assembly was connected to the electronic barostat. The studies were recorded on a computerised system and stored for later analysis. After a 30 minute equilibration period, during which the baseline operating pressure was set as described above and baseline recordings were obtained, gastric compliance was measured. Premeal gastric sensation was measured 15 minutes after the end of compliance measurements by standard phasic bag distensions $(4,8,12 \mathrm{~mm} \mathrm{Hg})$ performed in random order. When the volume within the bag had returned to baseline values following the last distension, premeal (fasting) bag volume fluctuations were monitored for at least 20 minutes. Thereafter, subjects drank $200 \mathrm{ml}$ (0.64 MJ; 55\% carbohydrate, 31\% fat, and $14 \%$ protein) of chocolate flavored Ensure (Abbott Laboratories, Columbus, Ohio, USA) with a straw during a five minute period. The chocolate drink was served at room temperature. Proximal gastric tone was monitored for at least 20 minutes after the meal. Gastric perception was then measured postprandially on two occasions as described above. After removal of the gastric tube, the somatic sensitivity was performed. The vagal function test was performed either on a separate day after a three hour fast or on the day of the intubated study at least three hours after the study meal. The gastric emptying study and the water bolus test were performed on separate days.

\section{DATA ANALYSIS}

Gastric emptying was summarised by the percentage remaining in the stomach at two and four hours, and orocaecal transit by percentage colonic filling of isotope at six hours after ingestion of the meal. The initial gastric distribution of the meal was calculated from the image taken immediately after the end of the meal ingestion (zero hour scan):

$$
\begin{aligned}
& \% \text { in proximal stomach } \\
& =\frac{\text { isotope activity in proximal stomach }}{\text { total isotope activity in stomach }}
\end{aligned}
$$

Gastric tone was estimated from the baseline volume of the polyethylene bag, as in previous studies. $^{32-34}$ Changes in both pressure and volume of the barostat bag were sampled as analogue signals at $4 \mathrm{~Hz}$ and converted to digital signals before entry into a computer. A customised computer method (VAXLAB, Digital Equipment Corp., Maynard, Mississippi, USA) was utilised to detect respiratory and motion artefacts and to separate baseline gastric tone and phasic volume peaks. For the accommodation response to meal ingestion, the averaged baseline barostat volume during the first 20 minutes postprandially was compared with the average value during the preprandial 20 minutes. We compared the percentage change in intrabag baseline volume between the patients and controls. The percentage change was used in order to normalise for interindividual differences in bag volume during fasting.

Gastric compliance was defined as the linear slope of a pressure-volume curve with values obtained during ramp inflations, where pressure $(\mathrm{mm} \mathrm{Hg})$ is represented on the $x$ axis and bag volume $(\mathrm{ml})$ on the $y$ axis.

Gastric phasic volume peaks were calculated as an area under the curve for the 20 minute premeal and postmeal periods. Phasic volume peaks were expressed as the barostat index (BI) per hour: $\mathrm{BI} / \mathrm{h}=\ln [$ (sum amplitudes $\times$ number peaks/h) + 1]. 
Table 1 Clinical characteristics of patients with non-ulcer dyspepsia (NUD)

\begin{tabular}{|c|c|c|c|c|c|c|c|c|}
\hline Patient & Age (years) & $\operatorname{Sex}$ & NUD symptoms & $\begin{array}{l}\text { Duration of } \\
\text { NUD (years) }\end{array}$ & $\begin{array}{l}\text { Associated } \\
\text { IBS }\end{array}$ & Personality assessment (MMPI) & H pylori status & Upper endoscopy \\
\hline 1 & 58 & M & Epigastric pain, early satiety, bloating & 10 & No & Hypochondriasis & Negative & Erythema, antrum \\
\hline 2 & 23 & $\mathrm{~F}$ & Epigastric pain, bloating & 3 & Yes & Normal & Negative & Normal \\
\hline 3 & 57 & $\mathrm{~F}$ & $\begin{array}{l}\text { Epigastric pain, nausea, vomiting, } \\
\text { bloating }\end{array}$ & 5 & No & Hypochondriasis, hysteria & Negative & Erythema, antrum \\
\hline 4 & 54 & $\mathrm{~F}$ & Epigastric pain, nausea, bloating & 4 & Yes & Depression, hypochondriasis & Negative & Normal \\
\hline 5 & 30 & M & $\begin{array}{l}\text { Epigastric pain, nausea, early satiety, } \\
\text { bloating }\end{array}$ & 9 & No & Normal & Negative & Erythema, antrum \\
\hline 6 & 46 & $\mathrm{~F}$ & $\begin{array}{l}\text { Epigastric pain, nausea, vomiting, } \\
\text { early satiety, bloating }\end{array}$ & 1.3 & Yes & Depression, hypochondriasis & Negative & Normal \\
\hline 7 & 28 & $\mathrm{~F}$ & Epigastric pain, early satiety, bloating & 2 & No & Normal & Negative & Erosions, pylorus \\
\hline 8 & 43 & M & Epigastric pain, nausea, early satiety & 0.7 & Yes & Depression, hypochondriasis & Negative & Erythema, antrum \\
\hline 9 & 54 & M & Epigastric pain, nausea, bloating & 3 & No & Normal & Negative & Normal \\
\hline 10 & 33 & $\mathrm{~F}$ & Epigastric pain, vomiting, bloating & 0.9 & No & Normal & Negative & Erythema, antrum \\
\hline 11 & 40 & $\mathrm{~F}$ & $\begin{array}{l}\text { Epigastric pain, nausea, vomiting, } \\
\text { bloating }\end{array}$ & 7 & Yes & Hypochondriasis & Negative & Normal \\
\hline 12 & 31 & M & Epigastric pain, early satiety, nausea & 6 & No & Normal & Negative & Normal \\
\hline 13 & 26 & M & Epigastric pain, nausea, early satiety & 3 & No & Schizoid personality & Positive & Erythema, fundus \\
\hline 14 & 50 & $\mathrm{~F}$ & Epigastric pain, bloating & 2 & No & Depression, anxiety & Positive & Erythema, antrum \\
\hline 15 & 27 & M & Epigastric pain, nausea, bloating & 5 & Yes & Normal & Positive & Erythema, antrum \\
\hline 16 & 40 & $\mathrm{~F}$ & Epigastric pain, nausea, bloating & 5 & No & Normal & Positive & Erosions, antrum \\
\hline 17 & 38 & M & Epigastric pain, nausea, vomiting & 10 & Yes & Normal & Positive & Erythema, antrum \\
\hline
\end{tabular}

Erosions were $\leqslant 4 \mathrm{~mm}$ diameter.

IBS, irritable bowel syndrome.

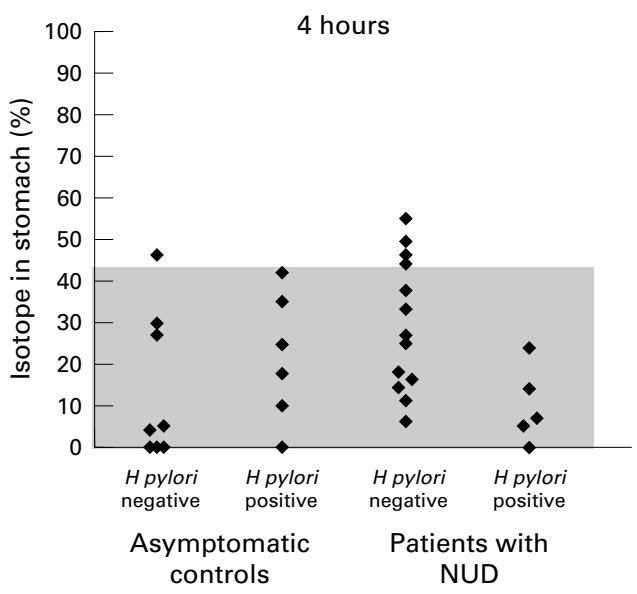

Figure 2 Gastric residual data at four hours. The shaded area shows normal ranges in our laboratory. ${ }^{23}$ NUD, non-ulcer dyspepsia.

The ratios of post:premeal measurements of phasic volume peaks were summarised as a barostat index ratio.

To assess gastric sensitivity, the individual scores for nausea, fullness, and discomfort on the seven point adjectival scale (marked 0 to 6 ) during each of the three distensions were summed to provide an aggregate perception score for each subject (minimal score 0 and maximal score 18 for each distension).

\section{STATISTICAL ANALYSIS}

The sample size for the study was based on $80 \%$ power (at $\alpha=0.05$ ) that assessed the variances of gastric emptying and postprandial accommodation in a previously studied group of healthy controls. All data are presented as mean values (SEM). Statistical comparisons between groups were performed by one way analysis of variance (ANOVA) with multigroup comparisons-that is, $H$ pylori negative and $H$ pylori positive patients with non-ulcer dyspepsia, and each dyspeptic group versus the respective asymptomatic controls unless otherwise stated (see below). These comparisons were performed for gastric tone, phasic events, and compliance. The Kruskal-Wallis test (one way ANOVA on ranks) was used for non-parametric data: gastric emptying, orocaecal transit, and initial distribution of the meal within the stomach.

As our previous study ${ }^{33}$ showed that the gastric accommodation response in asymptomatic volunteers was significantly different among $H$ pylori negative and $H$ pylori positive participants, all comparisons for gastric motor functions are made with the two respective subgroups of controls. However, as gastric and somatic sensation were not different for $H$ pylori negative and $H$ pylori positive asymptomatic volunteers, we pooled sensation data for comparisons with the two dyspeptic groups. Fisher's exact test was used to compare the proportion of the two patient groups with abnormal sensation.

Comparisons between $H$ pylori positive and $H$ pylori negative dyspeptics were assessed at $\alpha=0.05$. Where multigroup comparisons were performed, a $\mathrm{p}$ value of less than 0.017 was considered to be statistically significant. Thus, Bonferroni's correction was applied to correct for three pairwise comparisons of the main end points (transit, accommodation, sensation)

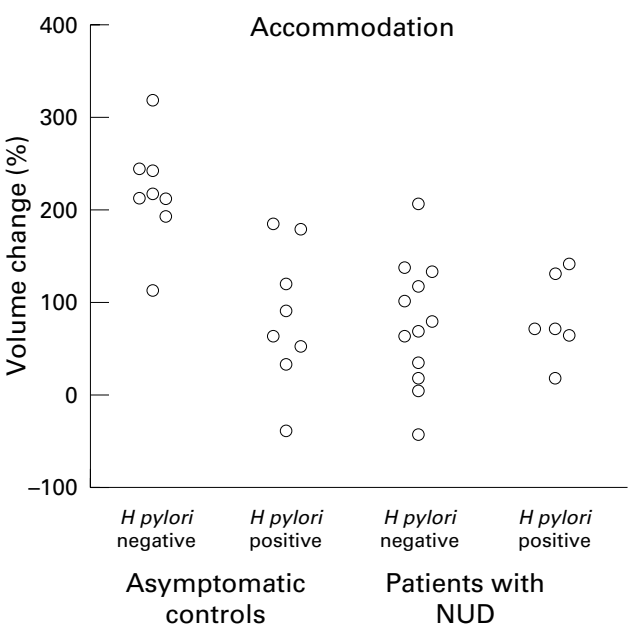

Figure 3 Individual accommodation data for all groups studied. NUD, non-ulcer dyspepsia. 
Table 2 Motor functions in patients with non-ulcer dyspepsia (NUD) and asymptomatic controls with and without Helicobacter pylori infection

\begin{tabular}{|c|c|c|c|c|}
\hline & $\begin{array}{l}\text { NUD/H pylori } \\
\text { negative }(n=12)\end{array}$ & $\begin{array}{l}\text { NUD/H pylori } \\
\text { positive }(n=5)\end{array}$ & $\begin{array}{l}\text { Controls/H pylori } \\
\text { negative }(n=8)\end{array}$ & $\begin{array}{l}\text { Controls/H pylori } \\
\text { positive }(n=8)\end{array}$ \\
\hline Gastric emptying ( $\%$ retained in stomach) at 2 hours & $62(5)$ & $70(18)$ & $46(8)$ & $57(5)$ \\
\hline Gastric emptying ( $\%$ retained in stomach) at 4 hours & $29(15)^{\star}$ & $10(4)$ & $14(6)$ & $16(6)$ \\
\hline Initial gastric meal distribution (\% in proximal stomach) & $71(5)$ & $76(3)$ & $80(3)$ & $76(4)$ \\
\hline Orocaecal transit ( $\%$ colonic filling at 6 hours) & $17(7)+$ & $40(3)$ & $43(9)$ & $24(6)$ \\
\hline Fasting gastric tone $(\mathrm{ml})$ & $210(32)$ & $185(35)$ & $145(17)$ & $178(20)$ \\
\hline Compliance $(\mathrm{ml} / \mathrm{mm} \mathrm{Hg})$ & $60(5)$ & $71(9)$ & $79(10)$ & $67(8)$ \\
\hline Accommodation ( $\%$ volume change from fasting) & $75(22) \ddagger$ & $69(18) \ddagger$ & $218(21)$ & $84(27) \ddagger$ \\
\hline Postprandial volume change $(\mathrm{ml})$ & $129(32) \ddagger$ & $133(48) \ddagger$ & $310(42)$ & $124(40) \ddagger$ \\
\hline Barostat index $(\mathrm{BI} / \mathrm{h})$ premeal & $8.96(0.6)$ & $9.07(0.4)$ & $9.59(0.4)$ & $9.59(0.4)$ \\
\hline Barostat index $(\mathrm{BI} / \mathrm{h})$ postmeal & $9.19(0.5)$ & $9.48(0.6)$ & $7.22(0.98)$ & $9.35(0.4)$ \\
\hline Barostat index ratio-postmeal:premeal & $1.1(0.6) \S$ & $1.05(0.07)$ & $0.75(0.1)$ & $0.98(1)$ \\
\hline Pancreatic polypeptide $(\mathrm{pg} / \mathrm{ml})$ : abnormal response & $1 / 12$ & $1 / 5$ & $0 / 8$ & $1 / 8$ \\
\hline
\end{tabular}

Results are expressed as mean (SEM).

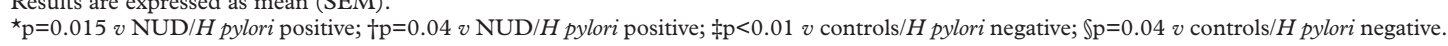

between controls and two dyspeptic groups, and between $H$ pylori positive and negative patients.

\section{Results}

CLINICAL CHARACTERISTICS OF PATIENTS

Table 1 summarises the clinical features of patients with non-ulcer dyspepsia. Patients had a mean symptom duration of 4.5 years; there was no significant difference in the duration of dyspepsia between $H$ pylori negative patients (3.7 (1) years) and $H$ pylori positive patients (5 (1.1) years). There was also no difference in sex, age, or body mass index (BMI) between patients and asymptomatic controls (control data not shown).

Overlap symptoms indicative of irritable bowel syndrome were present in seven of 17 patients with non-ulcer dyspepsia. By MMPI, eight of the 17 dyspeptic patients had significant psychopathology, chiefly somatisation and depression.

Upper endoscopy revealed antral erythema in five of $12 \mathrm{H}$ pylori negative patients and four of five $H$ pylori positive patients. One patient in each group had a single antral or pyloric erosion.

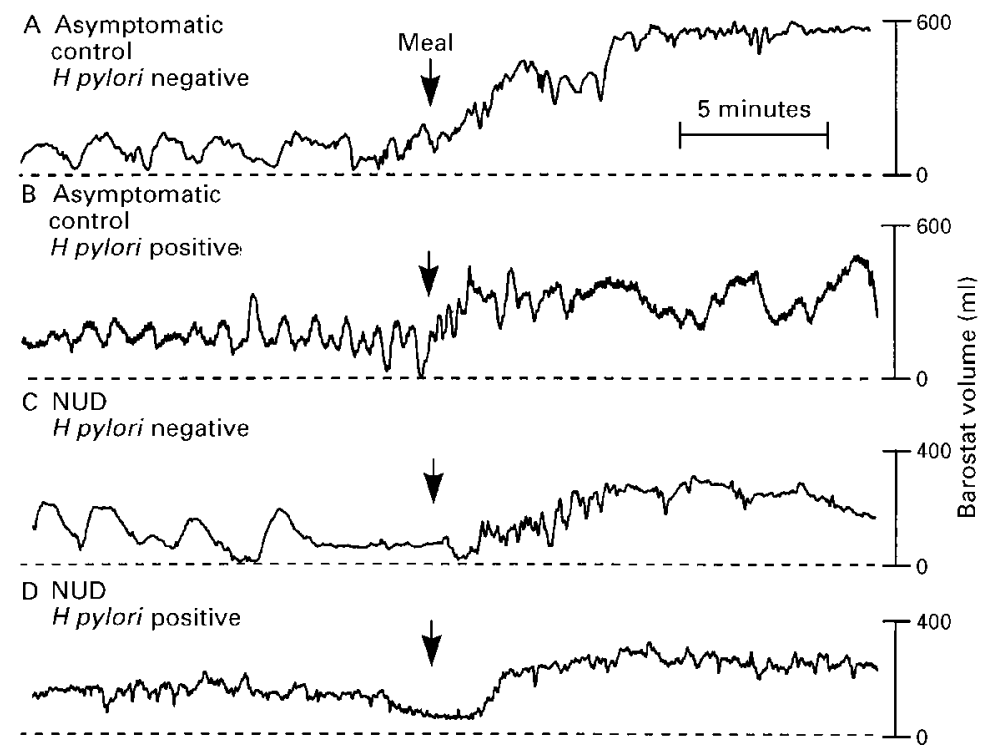

Figure 4 Representative tracings of gastric relaxation (accommodation) induced by meal ingestion. NUD, non-ulcer dyspepsia.
GASTRIC EMPTYING, INTRAGASTRIC MEAL DISTRIBUTION, AND OROCAECAL TRANSIT Overall group comparison of patients and controls showed that gastric emptying at four hours (fig 2) was significantly different $(\mathrm{p}=0.036)$; at two hours it was not $(\mathrm{p}=0.1) . H$ pylori negative patients had slower gastric emptying at four hours than $H$ pylori positive patients $(\mathrm{p}=0.015)$ and $H$ pylori negative asymptomatic controls $(\mathrm{p}=0.05)$. However, only four of $12 \mathrm{H}$ pylori negative patients had delayed gastric emptying relative to a large cohort of healthy subjects studied with the same test. ${ }^{24}$ The group of patients who were $H$ pylori positive had similar gastric emptying compared with their controls.

Initial intragastric meal distribution $(p=0.5)$ and orocaecal transit $(p=0.06)$ were not significantly different in the four groups. However, subgroup analysis showed that the percentage of colonic filling tended to be less in $H$ pylori negative dyspepsia compared with the $H$ pylori positive dyspepsia group $(\mathrm{p}=0.04)$.

\section{ABDOMINAL VAGAL FUNCTION}

In each of the dyspepsia groups, there was one patient with an abnormal pancreatic polypeptide response to modified sham feeding (table 2).

PROXIMAL GASTRIC TONE, PHASIC ACTIVITY, AND COMPLIANCE

Fasting proximal gastric tone and gastric compliance were similar in all groups (table 2). The gastric accommodation response to meal ingestion in $H$ pylori positive asymptomatic controls and dyspeptics, and in $H$ pylori negative dyspeptics was significantly lower compared with $H$ pylori negative controls ( $\mathrm{p}<0.01$; fig 3 ). There was no statistically significant difference between the two groups of dyspeptics. Eight of $12 H$ pylori negative patients had a lower accommodation than any of the $H$ pylori negative controls. Figure 4 shows representative examples of the accommodation response in the early postprandial period.

Phasic contractility of the proximal stomach (barostat index in table 2) in the fasting period was generally similar in all groups; however, the $H$ pylori negative asymptomatic controls had a lower postmeal phasic response resulting in a lower barostat index ratio than in the $H$ pylori negative patients. 

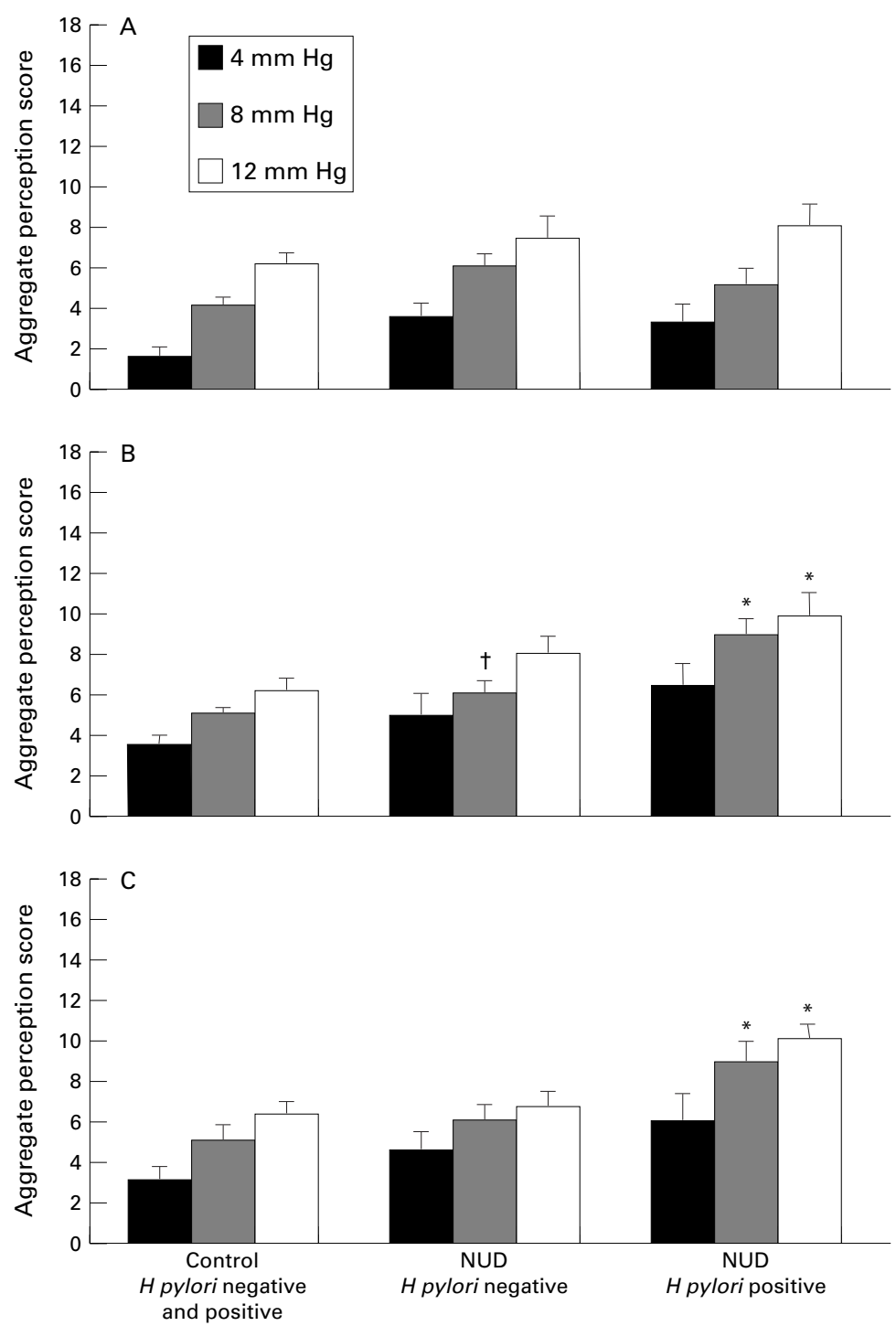

Figure 5 Aggregate sensation scores during fasting, early, and late postprandial periods in response to 4, 8, and $12 \mathrm{~mm} \mathrm{Hg}$ distensions above baseline operating pressure. NUD, non-ulcer dyspepsia. ${ }^{\star} p \leqslant 0.01$ versus asymptomatic controls; $t p<0.017$ versus asymptomatic controls. and $4 / 5$ dyspeptics in the late postprandial period. The proportion of $H$ pylori positive and $H$ pylori negative patients with increased sensitivity was not significantly different.

WATER BOLUS TEST

The ingested volume of cold water required to evoke abdominal fullness was similar in the asymptomatic control group (938 (75) $\mathrm{ml}$ ) and $H$ pylori negative $(833(67) \mathrm{ml})$ or positive dyspeptic patients $(679(174) \mathrm{ml})$.

SOMATIC SENSITIVITY

There were no significant differences in cold pain rating and the maximum time of cold pain tolerance between $H$ pylori negative dyspeptics (77 (5) $\mathrm{mm}$ and 119 (31) seconds respectively) or $H$ pylori positive dyspeptics (86 (4) $\mathrm{mm}$ and 56 (18) seconds), and asymptomatic controls (77 (5) $\mathrm{mm}$ and 145 (27) seconds).

\section{Discussion}

In this study, the most frequent physiological abnormality of the stomach in patients with non-ulcer dyspepsia was impaired accommodation in the postprandial period $(n=12 / 17)$. By contrast, 8/17 had increased sensitivity early postprandially and 4/17 delayed gastric emptying. A preliminary report by Salet et al also suggests that impaired accommodation is a common pathophysiological finding in dyspeptics. ${ }^{39}$ This suggests that diastolic dysfunction of the stomach may contribute to symptoms such as early satiety and bloating in dyspepsia. In most studies, gastric compliance in non-ulcer dyspepsia has been reported to be normal, ${ }^{12-14}$ although Salet et al suggested a slight but significant increase in gastric compliance. ${ }^{40}$ The impaired accommodation response postprandially was not associated with a different distribution of the meal within the stomach in the dyspeptics or asymptomatic controls. This contrasts with previous observations of Scott and colleagues ${ }^{41}$ and Troncon et al. ${ }^{6}$

Postprandially, gastric sensitivity was consistently increased in patients with $H$ pylori gastritis; those who were not infected with the organism had higher perception scores during only one of six sensation tests postprandially. Gastric hypersensitivity was observed in four of $12 \mathrm{H}$ pylori negative and four of five $\mathrm{H}$ pylori positive patients. The proportions of hypersensitive patients in the two groups were not significantly different. Holtmann and coworkers $^{42}$ have suggested that patients with higher IgG titres against $H$ pylori tended to have greater duodenal sensitivity than other dyspeptics and controls. These intriguing observations and the role of wall tension in gastric sensation require further study. Holtmann and coworkers $^{43}$ also recently reported reduced vagal efferent function in dyspeptics who had lowered gastric thresholds for first perception; they attributed to the vagus an antinociceptive role, which is lost in dyspeptics, resulting in greater gastric sensitivity. However, in the absence of corrections for differences in viscus volume (accommodation), which may result from vagal efferent dysfunction, the correlation 
H pylori negative $(\mathrm{n}=12)$

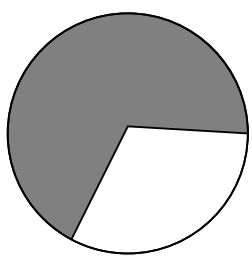

Impaired accommodation

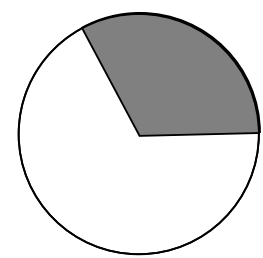

Hypersensitivity

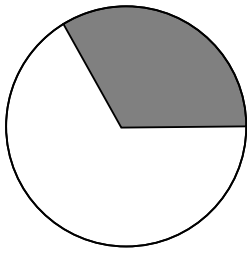

Delayed emptying

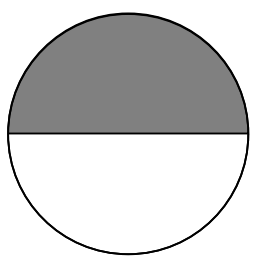

Abnormal MMPI
H pylori positive $(\mathrm{n}=5)$

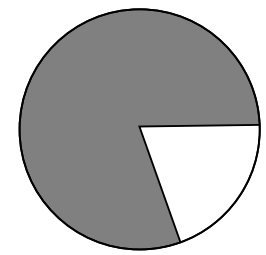

Impaired accommodation

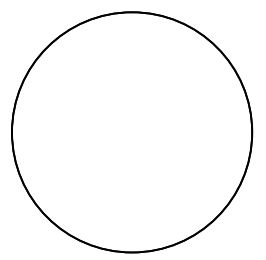

Delayed emptying

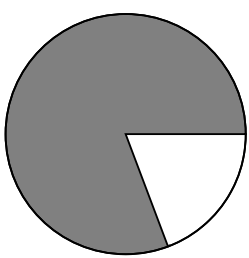

Hypersensitivity

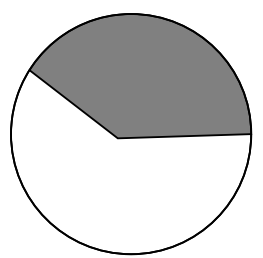

Abnormal MMPI

Abnormal

Normal

Figure 6 Distribution of impaired accommodation, delayed gastric emptying, gastric hypersensitivity, and abnormal reports on MMPI in patients with non-ulcer dyspepsia with and without H pylori infection.

between sensory thresholds and vagal efferent dysfunction remains speculative.

Currently the role of wall tension in determining gastric sensation is being extensively evaluated in pharmacological studies ${ }^{31}{ }^{44}$; Ohowever, there are no reports that assess wall tension and its modulation in dyspepsia.

The abnormal motor function of the proximal stomach in dyspepsia was initially suggested by Coffin et al who documented hyporeactivity (or reduced reflex fundic relaxation) in response to duodenal distension; however, there was no evidence of impaired fundic tone or compliance per se in the previous study. ${ }^{45}$ We have documented in a small number of patients the fact that at the time when dyspeptic patients develop symptoms (the postprandial period), there is abnormal gastric accommodation and gastric hypersensitivity in those who are $H$ pylori positive. As the presence of $H$ pylori was associated with a similarly reduced accommodation response in healthy subjects, ${ }^{33}$ the significance of reduced accommodation in $H$ pylori positive patients is unclear. These observations clearly need to be evaluated in a larger number of patients. Gastric hypersensitivity is highly prevalent in these patients ${ }^{46}$ and its mechanism remains to be fully elucidated.

The most striking differences in gastric accommodation were observed between $H$ pylori negative dyspeptics and controls, suggesting that a neuromuscular disturbance may be more easily shown in those patients who are $H$ pylori negative. A similar concept was suggested by Stanghellini et al who found that gastric emptying delay was more frequently encountered in $H$ pylori negative dyspeptics. ${ }^{18}$ Troncon et al speculated that it may be due to vagal dysfunction, as in their study postprandial gastric pressures were similar in patients with functional dyspepsia or postvagotomy. ${ }^{11}$ Our studies show that among 17 patients, vagal efferent function was abnormal in only two patients. This may reflect the lower sensitivity of the sham feeding test relative to insulin hypoglycaemia ${ }^{28}$; our data contrast with those recently reported by others who noted a failure of pancreatic polypeptide to increase after insulin induced hypoglycaemia in five of seven patients. ${ }^{43}$ On the other hand, we chose the sham feeding response for its greater specificity and our previous experience of its validity in patients with definite vagotomy. ${ }^{29}$

The significance of the increased phasic volume events in $H$ pylori negative dyspeptics compared with asymptomatic controls is unclear. The average frequency of phasic "contractions" is one per minute, which corresponds to the frequency of phasic activity noted in other studies, ${ }^{47}$ and cannot be attributed to respiration or movement "artefact". As previous human studies in the stomach ${ }^{32}$ and colon ${ }^{48}$ showed that the barostat bag technique is capable of detecting phasic reductions with larger baseline bag volumes than those observed in the stomach, the reduced phasic events in asymptomatic subjects cannot be explained by a technical deficiency. It is likely, therefore, that the increased phasic events in the poorly accommodating stomach of patients with non-ulcer dyspepsia is real; these phasic events may represent corpus contractions, similar to the type I contractions identified by Hightower and Code ${ }^{49}$ and are stimulated by the meal located in the gastric body.

The influence of psychological state, as assessed by the MMPI, showed a somatic focus and depression in eight of 17 patients, confirming other observations in the literature. ${ }^{50}$ It is plausible that gastric dysfunction may be the result of altered central modulation of motor or 
sensory functions. Physical and psychological stress alter gastric motor functions, ${ }^{51-54}$ including fundic tone,${ }^{55}$ but it has never been convincingly shown that somatoform disorders or established psychiatric traits per se actually alter gastric accommodation or sensory functions. Alternatively, the profiles may simply be consistent with these patients' chronic medical difficulties. Regardless, these data suggest that psychophysiological disturbances of gastric sensorimotor functions in dyspeptics are worthy of further investigation.

The distribution of impaired gastric accommodation, emptying, and hypersensitivity, and abnormal MMPIs among $H$ pylori negative and positive dyspeptic patients is summarised in fig 6. Several patients had more than one of these abnormalities; the sample size was clearly too small to assess the relative contributions by logistic regression analysis. Furthermore, the sample size for $H$ pylori positive dyspepsia may have contributed to some of the observations and requires further confirmation in larger samples.

In summary, in this group of patients with non-ulcer dyspepsia the most common pathophysiological disturbance is impaired accommodation or diastolic dysfunction. Reduced accommodation and delayed gastric emptying seem to be important in $H$ pylori negative dyspeptics; increased sensitivity of the stomach postprandially seems to be important in $H$ pylori positive dyspeptics. New neuropharmacological approaches to modulate proximal gastric motor and sensory functions are needed in order to understand the mechanisms controlling accommodation and gastric sensation in these patients. These studies might lead to novel therapies for functional dyspepsia. Data from our laboratory suggest that nitric oxide donors can enhance gastric relaxation and that the $\alpha_{2}$ adrenergic agonist, clonidine, relaxes stomach tone and reduces pain perception during gastric distension. ${ }^{44}$

This work was presented in part at the Annual Meeting of the American Gastroenterological Association in May 1996 (Gastroenterology 1996;110:A752). Dr Thumshirn was supported by troenterology 1996;110:A752). Dr Thumshirn was supported by
a grant from the Swiss National Science Foundation and a grant from the Swiss National Science Foundation and Schweizerische Stiftung fuer med biol Stipendien. This study
was supported in part by General Clinical Research Center was supported in part by General Clinical Research Center
grant no. RR00585 from the National Institutes of Health, grant no. RR00585 from the National Institutes of Health,
Bethesda, Maryland. We thank Mrs Cindy Stanislav for Bethesda, Maryland. We thank Mrs Cindy Stanislav for
excellent secretarial assistance, Dr G G Klee and the staff in the excellent secretarial assistance, Dr G G Klee and the staff in the Immunochemical Core Laboratory, and Dr Lee A Forstrom for technical advice

1 Barbara L, Camilleri M, Corinaldesi R, et al. Definition and investigation of dyspepsia-consensus of an international investigation of dyspepsia-consensus of an inter
ad hoc working party. Dig Dis Sci 1989;34:1272-6.

2 Talley NJ, Zinsmeister AR, Schleck CD, et al. Dyspepsia and Talley NJ, Zinsmeister AR, Schleck CD, et al. Dyspepsia and dyspepsia subgroups: a pop

3 Camilleri M. Nonulcer dyspepsia: a look into the future. Mayo Clin Proc 1996;71:614-22.

4 Greydanus MP, Vassallo M, Camilleri M, et al. Neurohormonal factors in functional dyspepsia: insights on pathophysiological mechanisms. Gastroenterology 1991;100: 1311-18.

5 Tucci A, Corinaldesi R, Stanghellini V, et al. Helicobacter pylori infection and gastric function in patients with chronic idiopathic dyspepsia. Gastroenterology 1992;103: 768-74.

6 Troncon LE, Bennett RJ, Ahluwalia NK, et al. Abnormal intragastric distribution of food during gastric emptying in intragastric distribution of food during gastric emptying

7 Stanghellini V, Ghidini C, Maccarini M, et al. Fasting and postprandial gastrointestinal motility in ulcer and nonulcer dyspepsia. Gut 1992;33:184-90.
8 Matsuo H, van Cutsem E, Wilmer A, et al. Impaired gastric compliance is related to weight loss in severe motility-like dyspepsia patients [abstract]. Gastroenterology 1994;106: dyspepsia

9 You CH, Lee KY, Chey WY, et al. Electrogastrographic study of patients with unexplained nausea, bloating, and vomiting. Gastroenterology 1980;79:311-14.

10 Jebbink HJ, Van Berge-Henegouwen GP, Bruijs PP, et al. Gastric myoelectric activity and gastrointestinal motility in patients with functional dyspepsia. Eur $\mathcal{f}$ Clin Invest 1995;25:429-37.

11 Troncon LEA, Thompson DG, Ahluwalia NK, et al. Relations between upper abdominal symptoms and gastric distension abnormalities in dysmotility like functional dyspepsia. Gut 1995;37:17-22.

12 Bradette M, Pare P, Douville P, et al. Visceral perception in health and functional dyspepsia. Crossover study of gastric distention with placebo and domperidone. Dig Dis Sci 1991;36:52-8.

13 Lemann M, Dederding JP, Flourie B, et al. Abnormal perception of visceral pain in response to gastric distention n chronic idiopathic dyspepsia. The irritable stomach syndrome. Dig Dis Sci 1991;36:1249-54.

14 Mearin F, Cucula M, Azpiroz F, et al. The origin of symptoms on the brain-gut axis in functional dyspepsia. Gastroenterology 1991;101:999-1006.

15 Richter JE. Stress and psychologic and environmental factors in functional dyspepsia. Scand $\mathcal{F}$ Gastroenterol 1991; 182:40-6.

16 Haug TT, Svebak S, Wilhelmsen J, et al. Psychological factors and somatic symptoms in functional dyspepsia: a comparison with duodenal ulcer and healthy controls. $\mathcal{F}$ Psychosom Res 1994;38:281-91.

17 Dooley CP, Cohen M, Fitzgibbons PL, et al. Prevalence of Helicobacter pylori infection and histologic gastritis in asymptomatic persons. N Engl f Med 1989;321:1562-6.

18 Stanghellini V, Tosetti C, Paternico A, et al. Risk indicators of delayed gastric emptying of solids in patients with funcof delayed gastric emptying of solids in patients with
tional dyspepsia. Gastroenterology 1996;110:1036-42.

19 Mearin F, de Ribot X, Balboa A, et al. Does Helicobacter pylori infection increase gastric sensitivity in functional dyspepsia? Gut 1995;37:47-51.

20 Talley NJ, Phillips SF, Melton LJ. A patient questionnaire to identify bowel disease. Ann Intern Med 1989;11:671-4.

21 Greene RL. The MMPI-2/MMPI: an interpretative manual. Boston: Allyn and Bacon, 1991.

22 Pearson JS, Rome HP, Swenson WM, et al. Development of a computer system for scoring and interpretation of Minnesota Multiphasic Personality Inventories in a medical clinic. Ann N Y Acad Sci 1965;126:684-95.

23 Camilleri M, Colemont LJ, Phillips SF, et al. Human gastric emptying and colonic filling of solids characterized by a new method. Am f Physiol 1989;257:G284-90.

24 Camilleri M, Zinsmeister AR, Greydanus MP, et al. Towards a less costly but accurate test of gastric emptying and small a less costly but accurate test of gastric emp
bowel transit. Dig Dis Sci 1991;36:609-15.

25 Schwartz TW, Holst JJ, Fahrenkrug J, et al. Vagal, cholinergic regulation of pancreatic polypeptide secretion. F Clin Invest 1978;61:781-9.

26 Taylor IJ, Feldman M, Richardson C, et al. Gastric and cephalic stimulation of human pancreatic polypeptide release. Gastroenterology 1978;75:432-7.

27 Koch MB, Go VLW, DiMagno EP. Can plasma human pancreatic polypeptide be used to detect disease of the exocrine pancreas? Mayo Clin Proc 1985;60:259-65.

28 Schwartz TW. Pancreatic polypeptide: a hormone under vagal control. Gastroenterology 1983;85:1411-25.

29 Camilleri M, Balm RK, Low PA. Autonomic dysfunction in patients with chronic intestinal pseudo-obstruction. Clin Auton Res 1993;3:95-100.

30 Azpiroz F, Malagelada J-R. Physiological variations in canine gastric tone measured by an electronic barostat. $\mathrm{Am}$ f Physiol 1985;248:G229-37.

31 Notivol R, Coffin B, Azpiroz F, et al. Gastric tone determines the sensitivity of the stomach to distention. Gastroenterology 1995;108:330-6.

2 Frank JW, Saslow SB, Camilleri M, et al. Mechanisms of accelerated emptying of liquids and hyperglycemia in patients with type II diabetes mellitus. Gastroenterology 1995;109:755-65.

33 Saslow SB, Thumshirn M, Camilleri M, et al. Influence of $\mathrm{H}$. pylori infection on gastric motor and sensory function in asymptomatic volunteers. Dig Dis Sci (in press).

34 Thumshirn M, Zinsmeister AR, Williams D, et al. Motor and sensory functions of the proximal stomach in rumination syndrome: evidence for "diastolic dysfunction", hypersensitivity, or behavioral disorder [abstract]. Gastroenterolsensitivity, or behavion
ogy 1997;112:A838.

35 Ford MJ, Camilleri M, Zinsmeister AR, et al. Psychosensory modulation of colonic sensation in the human transverse and sigmoid colon. Gastroenterology 1995;109:1772-80.

36 Bharucha AE, Camilleri M, Ford MJ, et al. Hyperventilation alters colonic motor and sensory function; effects and mechanisms in humans. Gastroenterology 1996;111:368-77.

37 Koch KL, Medina M, Xu L, et al. Gastric myoelectric responses to physiological stomach distention in humans [abstract]. Gastroenterology 1994;106:A525.

38 Ford MJ, Camilleri M, Joyner MJ, et al. Autonomic control of colonic tone and the cold pressor test. Gut 1996;39:125-9.

39 Salet GAM, Samsom M, Roelofs JMM, et al. Responses to gastric distention in functional dyspepsia [abstract]. gastric distention in function
Gastroenterology 1995;108:A681.

40 Salet GAM, Samsom M, Roelofs JMM, et al. Responses to gastric distention in functional dyspepsia. Gut 1998;42:823-9. 
41 Scott AM, Kellow JE, Shuter B, et al. Intragastric distribution and gastric emptying of solids and liquids in of symptom subgroups and H. pylori-asscociated gastritis. Dig Dis Sci 1993;38:2247-54

42 Holtmann G, Talley NJ, Goebell H. Association between $\mathrm{H}$ pylori, duodenal mechanosensory thresholds, and small intestinal motility in chronic unexplained dyspepsia. Dig Dis Sci 1996;41:1285-91.

43 Holtmann G, Goebell H, Jockenhoevel F, et al. Altered vagal and intestinal mechanosensory function in chronic unexplained dyspepsia. Gut 1998;42:501-6.

44 Thumshirn M, Burton DD, Zinsmeister AR, et al. Modulation of gastric sensory and motor functions by nitrergic and $\alpha$-adrenergic agents [abstract]. Gastroenterology 1997;112: A837.

45 Coffin B, Azpiroz F, Guarner F, et al. Selective gastric hypersensitivity and reflex hyporeactivity in functional dyspepsia Gastroenterology 1994;107:1345-51.

46 Mertz H, Fullerton S, Naliboff B, et al. Symptoms and visceral perception in severe functional and organic dyspepsia. Gut 1998;42:814-22.

47 Azpiroz F, Malagelada J-R. Gastric tone measured by an electronic barostat in health and postsurgical gastroparesis. Gastroenterology 1987;92:934-43.
48 von der Ohe MR, Hanson RB, Camilleri M. Comparison of simultaneous recordings of human colonic contractions by manometry and a barostat. Neurogastroent $213-22$

49 Hightower NC Jr, Code CF. The quantitative analysis of antral gastric motility records in normal human beings, with a study of the effects of neostigmine. Proc Staff Mayo Clin 1950;25:697-704.

50 Kawakami H, Hongo M, Okuno Y, et al. Personality deviaion and gastric motility in patients with functional dyspepsia. F Clin Gastroenterol 1995;21:S179-84.

51 Camilleri M, Malagelada J-R, Kao PC, et al. Gastric and autonomic resonses to stress in functional dyspepsia. Dig Dis Sci 1986;31:1169-77.

52 Wolf S, Wolff HG. Human gastric function. New York: Oxford University Press, 1947.

53 Thompson DG, Richelson E, Malagelada J-R. Pertubation of gastric emptying and duodenal motility through the of gastric emptying and duodenal motility through the
central nervous system. Gastroenterology 1982;83:1200-6.

54 Thompson DG, Richelson E, Malagelada J-R. Pertubation of upper gastrointestinal function by cold stress. Gut 1983; of upper gastri $24: 277-83$.

55 Zacchi P, Mearin F, Malagelada J-R. Effect of experimental cold pain stress on gastroesophageal junction. Dig Dis Sci 1994;39:641-7. 